\title{
ESTUDO PROSPECTIVO DE ÁCIDO LÁTICO PRODUZIDO POR LEVEDURAS EM GLICEROL BRUTO
}

Leandro Rodrigues Doroteu ${ }^{1 *}$, Fabricio de Andrade Raymundo ${ }^{2}$, Rogerio de Jesus Camargo Emidio $^{3}$, Marcilene Cordeiro Gomes ${ }^{4}$, Camila Alves Areda ${ }^{5}$, Eliana Fortes Gris ${ }^{6}$, Grace Ferreira Ghesti $^{7}$, Paulo Gustavo Barboni Dantas Nascimento ${ }^{8}$, Nadia Skorupa Parachin ${ }^{9}$, Eduardo Antonio Ferreira $^{10}$

1,2,3,4,5,6,7,8,9,10 Programa de Pós Graduação em Propriedade Intelectual e Transferência de Tecnologia para a Inovação ponto focal UnB -PROFNIT, Brasília, DF, Brasil.

Rec.:14/07/2017. Ace.:11/01/2018

\section{RESUMO}

O presente trabalho é um estudo prospectivo acerca da produção de poli(ácido lático) (PLA) por leveduras utilizando resíduos industriais (glicerol) como fonte de energia. O PLA é a base para a produção de plásticos biodegradáveis (biopolímeros) produzidos em grande escala, a partir de subprodutos da indústria do biodiesel - fontes renováveis. A produção por rota biológica, além da solução no descarte de subprodutos industriais, amplia a utilização do PLA, destacando-se a indústria cosmética e para aplicações no corpo humano, como preenchimento facial, agregando valor ao produto. Utilizou-se como metodologia a tendência de pesquisa, medida pela produção de artigos científicos, em conjunto com a análise de registro de patentes. Optou-se pela utilização de quatro as bases: Espacenet e Patentscope (patentes); Web of Science e Google Acadêmico (artigos). Os resultados demostraram que a tecnologia em questão se encontra em nível de desenvolvimento em relação ao ciclo de vida da tecnologia, como uma tecnologia em estágio de escalonamento, ainda em andamento. Com base nas patentes analisadas foi possível verificar que o maior recorte das tecnologias dessa produção está entre os TRL4 a TRL6. De modo geral, a prospecção aponta uma promissora perspectiva na produção de PLA por leveduras a partir de glicerol para a indústria.

Palavras-chave: Biopolímeros. Poli(ácido lático). Leveduras.

\section{PROSPECTIVE STUDY OF LACTIC ACID PRODUCED BY YEAST IN GROSS GLYCEROL}

The present work describes a prospective study regarding the production of polylatic acid (PLA) by living organisms, yeasts, using glycerol an industrial waste form the biodiesel industry as a substrate. PLA is the basis for the production of biodegradable plastic (biopolymers) produced on a large scale from a by-product of the biodiesel industry - renewable resources. Therefore the route proposed here is environmentally friendly. The production through a biological route, beyond the solution for industrial residues discharge, expands the range of applications of the PLA for cosmetic industry and for others uses on/in the human body, adding value to the product. This study employed the research trend as survey methodology, gauged by the generation of scientific papers, along with the examination of patent registration. Four databases were sorted for the present prospection: Espacenet and Patentscope (patents); Web of Science and Google Scholar (papers). The results demonstrated that the technology has been at developmental level in relation to the technology lifecycle, as a scale up technology, still in development. Based on the analyzed patents, it was possible to verify that the greatest stage gate of the production technologies is between TRL5 and TRL7. Overall, the prospect study indicates a possible outlook to produce pure Polylatic acid from glycerol.

Keywords: Biopolymers. Polylatic Acid. Yeast.

Área tecnológica: Biotecnologia, biomateriais, transferência de tecnologia.

*Autor para correspondência: doroteu.leandro@gmail.com 


\section{INTRODUÇÃO}

O ácido lático é um ácido orgânico produzido por diversos organismos a exemplo de bactérias, fungos, leveduras e microalgas. Tem ampla aplicação industrial em seguimentos como alimentos, fármacos, têxteis, couro e também pode ser processado na indústria química o que lhe possibilita outras aplicações. Devido a esses fatores apresenta um amplo potencial de mercado (LIMA, et. al. 2016).

Uma das formas de processamento industrial do ácido lático é a sua utilização como monômero (base de polímeros) utilizado para a produção de poli(ácido lático) (PLA) biodegradável. Sua aplicação industrial é potencializada devido às suas características químicas de polímero biocompatível com o organismo humano e à sustentabilidade ecológica (DATTA; HENRY, 2006).

O poli(ácido lático) (PLA) é considerado substituto do plástico convencional, feito a partir de derivado de petróleo. Assim, é uma possibilidade de substituição de um produto industrial (plástico convencional), produzido a partir de fonte esgotável (derivado de petróleo), por um produto a base de uma fonte vegetal, portanto renovável, que serve às mesmas funções sendo sustentável e biodegradável (SURYANEGARA; NAKAGAITO; YANO, 2009).

Em estudo prospectivo realizado no ano de 2014 o número de patentes brasileiras relacionadas a embalagens biodegradáveis depositadas, até então, foi considerado inexpressivo. O Brasil não possuía nem uma dezena enquanto o país líder apresentava em torno de oitenta, e o segundo colocado cerca de cinquenta patentes. Dessa forma "Os Estados Unidos é o país que maior detém a tecnologia de produção dos polímeros biodegradáveis e o Brasil ainda ocupa um espaço muito pequeno no cenário mundial como detentor desta tecnologia, sendo necessários incentivos que visem aumentar o cenário inovativo do país." (MACHADO, et. al. 2014).

Outro estudo prospectivo analisou polímeros biocompatíveis aplicados à engenharia de tecidos e medicina regenerativa a partir da produção de artigos e depósito de patentes. Nesse estudo os polímeros receberam destaque, e o PLA foi citado como uma das possibilidades. "As tecnologias foram consideradas emergentes e de interesse em pesquisas científicas com potencial campo de crescimento." (ROCHA; QUINTELLA; TORRES, 2014).

Em estudo de Cardoso; Souza e Guimarães (2017) relacionado a depósito de patentes de embalagens antimicrobianas em alimentos, verificou-se que dentre os doze tipos de polímeros possíveis para se trabalhar a tecnologia por eles analisadas, duas patentes utilizaram o PLA. Constatou-se também que o setor ainda é dominado por polímeros de base sintética, porém os pesquisadores mencionaram a importância e o interesse do desenvolvimento da tecnologia de polímeros biodegradáveis também no setor de embalagens ativas para alimentos como uma forma de sustentação ambiental. Cabe destacar que o setor de embalagens antimicrobianas é dominado por polímeros sintéticos "os sintéticos representaram a maior percentagem, $91 \%$ das patentes, enquanto os naturais apenas $9 \%$ ".

Dentre os microrganismos que podem processar o ácido lático escolheu-se para o presente estudo as leveduras utilizadas em processos de fermentação, tendo como substratos subprodutos industriais como o subproduto da indústria de biodiesel, glicerol bruto, resíduo gerado na proporção de $10 \%$ da produção do biodiesel, que segundo dados da Agência Nacional de Petróleo, Gás Natural e Biocombustíveis, foi de 1,6 bilhões de litros no Brasil em 2016, mas já chegou ao número de 2,9 bilhões de litros em 2013 (ANP, 2016).

Verifica-se, portanto, que a indústria tem dificuldade de descarte de resíduos que apresentam potencial energético (fonte de carbono) mas que podem servir como base para processos de fermentação por leveduras preparadas para suportar o grau de toxicidade do material. 


\section{METODOLOGIA}

A atividade caracterizou-se como uma pesquisa quantitativa em fontes primárias representadas palas próprias redações das patentes pesquisadas a partir de dois repositórios de patentes Espacenet (EPO) (Espacenet, 2017) e Patentscope (Patentscope, 2017) e dois repositórios de artigos (Google Acadêmico e Web of Science) (Google Acadêmico, 2017 e Web of Science, 2017) e pelo número de produção de artigos científicos relacionados à tecnologia de utilização de leveduras para a produção de ácido lático utilizando as palavras em língua inglesa: Yeast, glycerol, poly lactic acid e lactic acid, associadas aos operadores booleanos and e or .

Com a aplicação dos operadores a busca foi aplicada aos termos: Yeast and glycerol, Lactic acid and yeast and glycerol, Lactic acid or yeast, Lactic acid or glycerol com seleção para a ocorrência dos termos no título ou no resumo. O que caracterizou a pesquisa como Bibliometria e análise de tendências. As buscas foram realizadas do dia 14 a 16 de junho de 2017.

Em um segundo momento a análise estatística "Na família de estatísticas, as principais técnicas são: Bibliometria (Research Profiling; Patent Analysis; Text Mining); Análise de Correlação; CrossImpact Analysis; Análise de Risco; Análise de Tendência de Impacto (Trend Impact Analysis [TIA]) (PORTER et al., 2004, apud DOS REIS et. al., 2016)." Utilizamos a tendência de pesquisa medida pela produção de artigos científicos em conjunto com a análise de registro de patentes.

\section{RESULTADOS E DISCUSSÃO}

Na busca de patentes no Patentscope foram encontradas 72 patentes, dessas 21 não tinham relação com a tecnologia de produção de poli(ácido lático) (PLA) em glicerol por meio de leveduras, restando assim 51 patentes, distribuídas entre os quatro argumentos pesquisados. Os resultados são apresentados na Tabela 1.

Tabela 1 - Resultado da pesquisa de patentes relacionadas com a tecnologia de produção de PLA em glicerol por meio de leveduras na base de dados do Patentscope.

\begin{tabular}{lc}
\hline \multicolumn{1}{c}{ Palavras-chave } & Patentscope \\
\hline Yeast and glycerol & 16 \\
Lactic acid and yeast and glycerol & 2 \\
Lactic acid or yeast & 20 \\
Lactic acid or glycerol & 13 \\
\hline
\end{tabular}

Fonte: Elaborado pelos autores (2017).

Observa-se na Tabela 1 que a expressão Lactic acid or yeast apresentou o maior número de resultados: 20, seguido de 16 resultados para Yeast and glycerol, 13 para Lactic acid or glycerol e em um refinamento maior da busca associando as palavras Lactic acid, yeast, glycerol pelo conectivo and apenas 2 depósitos.

Após a determinação do número de patentes relacionadas à pesquisa foi feito um estudo da evolução das patentes relacionando ao ano, buscando uma descrição cronológica dos depósitos relacionados à tecnologia (Figura 1).

Figura 1 - Evolução anual de depósitos de patentes relacionadas com a tecnologia de produção de PLA em glicerol por meio de leveduras na base de dados do Patentscope.

DOROTEU, L.R et al.. Estudo prospectivo de ácido lático produzido por leveduras em glicerol bruto. 


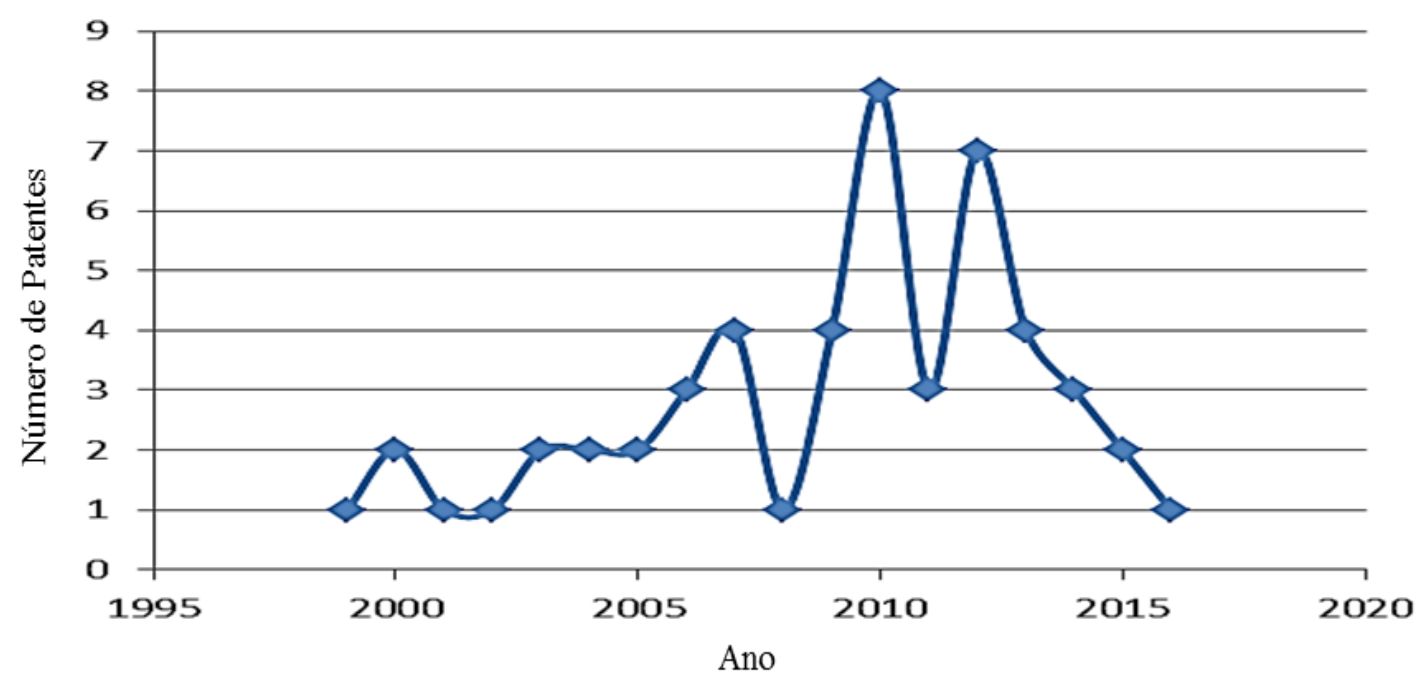

Fonte: Elaborado pelos autores (2017).

Verificou-se que o primeiro depósito foi no ano de 1998, tendo seu ápice no ano de 2010, observando-se uma diminuição gradual do ano de 2013 a 2016. Estudos de patentes relacionadas a polímeros com agentes antimicrobianos ou embalagens ativas datam do final da década de 1980. "O ano de 1988, foi o início dos depósitos de patentes voltadas a polímeros incorporados com agentes antimicrobianos" (CARDOSO; SOUZA; GUIMARÃES, 2017). Apesar da produção por biotecnologia desses polímeros ativos, ainda há produção de polímeros sintéticos, então é representativo saber que o primeiro depósito relacionado à produção de ácido lático em glicerol, base para polímeros biológicos, como demonstrado na Figura 1 é de 1998.

A constatação do início dos depósitos de polímeros biodegradáveis é coerente com o trabalho de Franchetti; Marconato (2006, p. 812) "Descobertos há cerca de 10 anos (informação prestada em 2004), os plásticos biodegradáveis, também denominados plásticos biológicos ou bioplásticos, hoje ainda têm uma participação mínima no mercado internacional." Submetido em 2004, portanto redigido nesse ano e publicado em 2006, a tecnologia atualmente conta com mais de duas décadas.

Como se observa na Figura 1, na década de 1990 e anos iniciais de 2000 as pesquisas eram bem incipientes com o depósito de uma ou duas patentes (ano de 1999 a 2005) chegando ao depósito de quatro apenas em 2007. Os anos com maiores números de depósitos foram os anos de 2010 com 8 depósitos e de 2012 com 7 depósitos. Analisando o contexto do início dessa produção e de seu pico observa-se que entre os anos de 2010 a 2012 foram depositadas 18 patentes. Esses momentos guardam relação com as agendas estabelecidas nos eventos Rio 92 (início) e Rio mais 20 (pico), marco inicial e reafirmação de compromissos ecológicos impactantes em mercados relacionados à tecnologia analisada (GUIMARÃES; FONTOURA, 2012).

Na distribuição entre os países, demonstrada na Figura 2, verifica-se que o país com maior número de patentes é a Coréia do Sul, com 11 patentes, o que corresponde a 21,56\% do total de depósitos analisados. Em segundo lugar, com 9 patentes $(17,64 \%)$ encontram-se o Brasil e a Coréia do Norte, seguidos do Japão (6 patentes - 11,76\%) e Portugal (5 patentes - 10\%). Os Estados Unidos e PCT possuem o mesmo número de patentes ( 3 patentes cada- 5,88\%), bem como Áustria, Rússia e China (2 patentes cada -3,92\%). Em último lugar encontra-se a Rússia com 1 patente o que equivale a $2 \%$ do total de patentes analisadas.

DOROTEU, L.R et al.. Estudo prospectivo de ácido lático produzido por leveduras em glicerol bruto. 
Figura 2 - Número de patentes relacionadas com a tecnologia de produção de PLA em glicerol por meio de leveduras depositadas por país na base de dados do Patentscope.

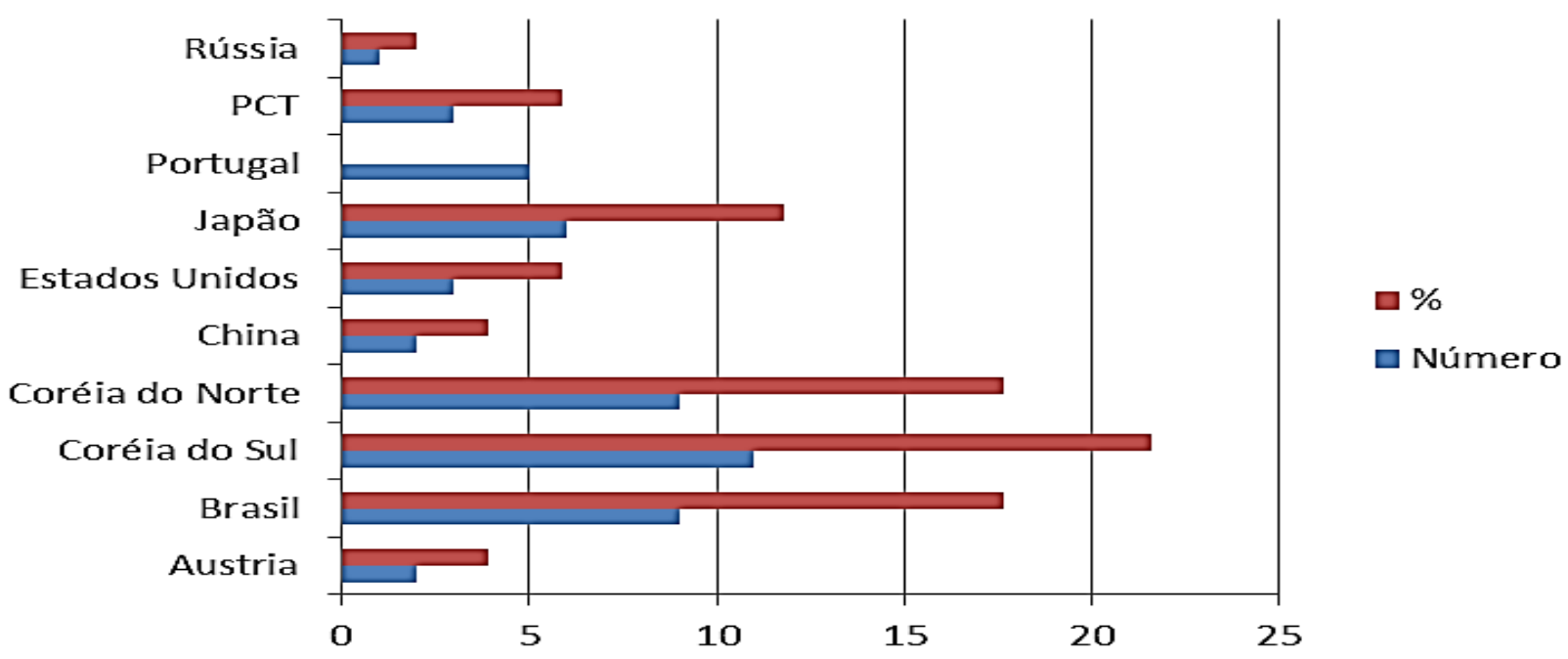

Fonte: Elaborado pelos autores (2017).

Ao associar os dados contidos nas Figuras 1 e 2 é possível verificar que apesar do pioneirismo japonês, país de onde se originou o primeiro depósito de 1998, atualmente merecem destaque nessa tecnologia a Coreia do Sul (11 depósitos), Coreia do Norte e Brasil (9 depósitos), seguidos pelo Japão (6 depósitos).

Os resultados da busca na base de patentes Espacenet, mais abrangente que a Patentscope, estão apresentados na Tabela 2. A pesquisa foi realizada com base nas mesmas expressões consultadas no título e abstract. Pela amplitude da base, que no geral apresentava mais de 10.000 resultados para cada consulta, optou-se por recortar também pela classificação da tecnologia apenas nas classificações a A e $\mathrm{C}$, classificações que estavam concentrados todos os resultados obtidos no Patentscope. Com esse recorte foi possível obter resultados compatíveis, resguardadas as proporções, com os apresentados na primeira base consultada conforme se observa na Tabela 2.

Tabela 2 - Resultado da pesquisa de patentes na base de dados do Espacenet.

\begin{tabular}{lc}
\hline \multicolumn{1}{c}{ Palavras-chave } & Espacenet \\
\hline Yeast and glycerol & 650 \\
Lactic acid and yeast and glycerol & 21 \\
Lactic acid or yeast & 199 \\
Lactic acid or glycerol & 199 \\
\hline
\end{tabular}

Fonte: Elaborado pelos autores (2017).

Verifica-se na Tabela 2 que os resultados obtidos em relação às expressões utilizadas foram diferentes dos resultados obtidos na base de dados Patentscope. A expressão Yeast and glycerol apresentou o maior número de resultados: 650, seguido de Lactic acid or yeast e Yeast Lactic acid or glycerol (199 cada) e Lactic acid, yeast, glycerol pelo conectivo and.

Além da busca em banco de dados de patentes o presente trabalho pretendeu também o levantamento bibliométrico. Para tanto, levando-se em conta o produto tecnológico pretendido: a DOROTEU, L.R et al.. Estudo prospectivo de ácido lático produzido por leveduras em glicerol bruto. 
produção de ácido lático por leveduras a partir de glicerol, foram empregados os mesmos argumentos de busca: Yeast and glycerol, Lactic acid and yeast and glycerol, Lactic acid or yeast, Lactic acid or glycerol nas bases Web of Science e Google Acadêmico.

Tabela 3 - Números de publicações em diferentes bases de dados.

\begin{tabular}{lccc}
\hline \multicolumn{1}{c}{ Palavras-chave } & Web of Science & Google Acadêmico & TOTAL \\
\hline Yeast and glycerol & 275 & 131 & 406 \\
Lactic acid and yeast and glycerol & 0 & 0 & 0 \\
Lactic acid or yeast & 98.357 & 6 & 98.363 \\
Lactic acid or glycerol & 36.196 & 2 & 36.196 \\
Produção de poli(ácido lático) (PLA) & 0 & 817 & 817 \\
\hline
\end{tabular}

Fonte: Elaborado pelos autores, 2017

Apesar da aparente abundância de produção acadêmica, ao se fazer um filtro do conteúdo que de fato tem relação com a tecnologia prospectada, observou-se uma pequena produção de trabalhos relativos à produção de PLA, de forma que na busca, tanto em língua portuguesa como em língua inglesa, não foi possível encontrar nenhum trabalho pelo título. A partir de uma análise dos conteúdos dos trabalhos localizados, 62 trabalhos podem ser relacionados aos termos, e destes, apenas 30 relacionados à produção de ácido lático por leveduras em glicerol. Assim verifica-se que a pesquisa de produção de ácido lático em glicerol é embrionária tanto no Brasil como no mundo, apresentando potencial de inovação bastante promissor. A Figura 3 apresenta a distribuição da produção dos artigos ao longo dos anos.

Figura 3 - Evolução anual dos artigos publicados nas bases Web of Science e Google Acadêmico relacionadas com a tecnologia de produção de PLA em glicerol por meio de leveduras.

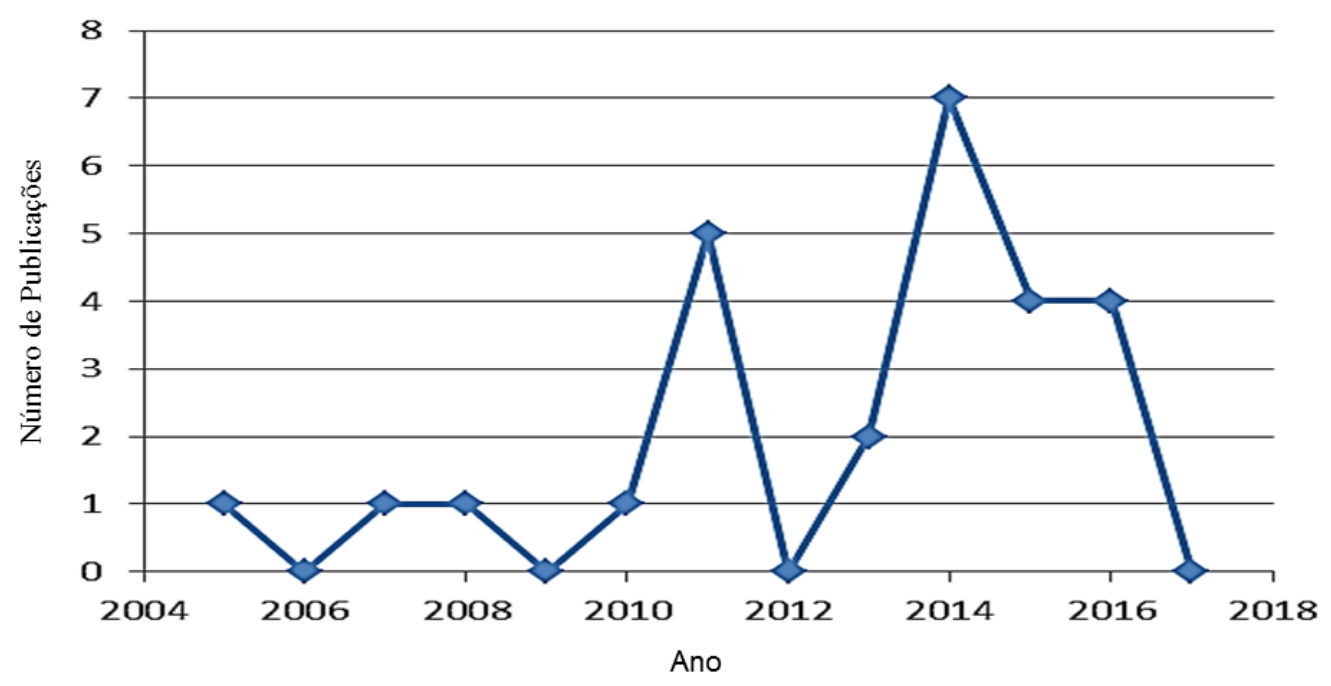

Fonte: Elaborado pelos autores (2017).

De modo geral pode-se observar que o número de publicações entre 2003 e 2010 foi de no máximo 1 artigo por ano. Em 2011 verifica-se um aumento significativo (5 artigos), seguido de um decréscimo em 2012. O auge se deu em 2014 com 7 artigos publicados, sendo seguido de um declínio expressivo nas publicações nos anos subsequentes para valores de 4 e 0 .

DOROTEU, L.R et al.. Estudo prospectivo de ácido lático produzido por leveduras em glicerol bruto. 
A busca em bases de artigos difere da busca em bases de patentes pelo fato de os artigos não possuírem classificações, e as informações contidas nos seus campos (títulos, palavras-chave, resumo) não seguem critérios estabelecidos como nas reivindicações das patentes. Essas informações dependem apenas do(s) autor(es) e/ou sugestões dos revisores (QUINTELLA, et.al., 2011), o que restringiu os resultados a partir de uma analise detalhada das buscas.

Um comparativo relevante para aferição da maturidade tecnológica da produção de ácido lático em glicerol pode ser expresso pela quantidade de patentes e de artigos. Esses dados são apresentados na Figura 4, sendo que a série 1 é relativa aos artigos e a série 2 às patentes.

Figura 4 - Evolução anual da publicação de artigos nas bases Web of Science e Google Acadêmico e patentes na base de dados do Patentscope relacionadas com a tecnologia de produção de PLA em glicerol por meio de leveduras.

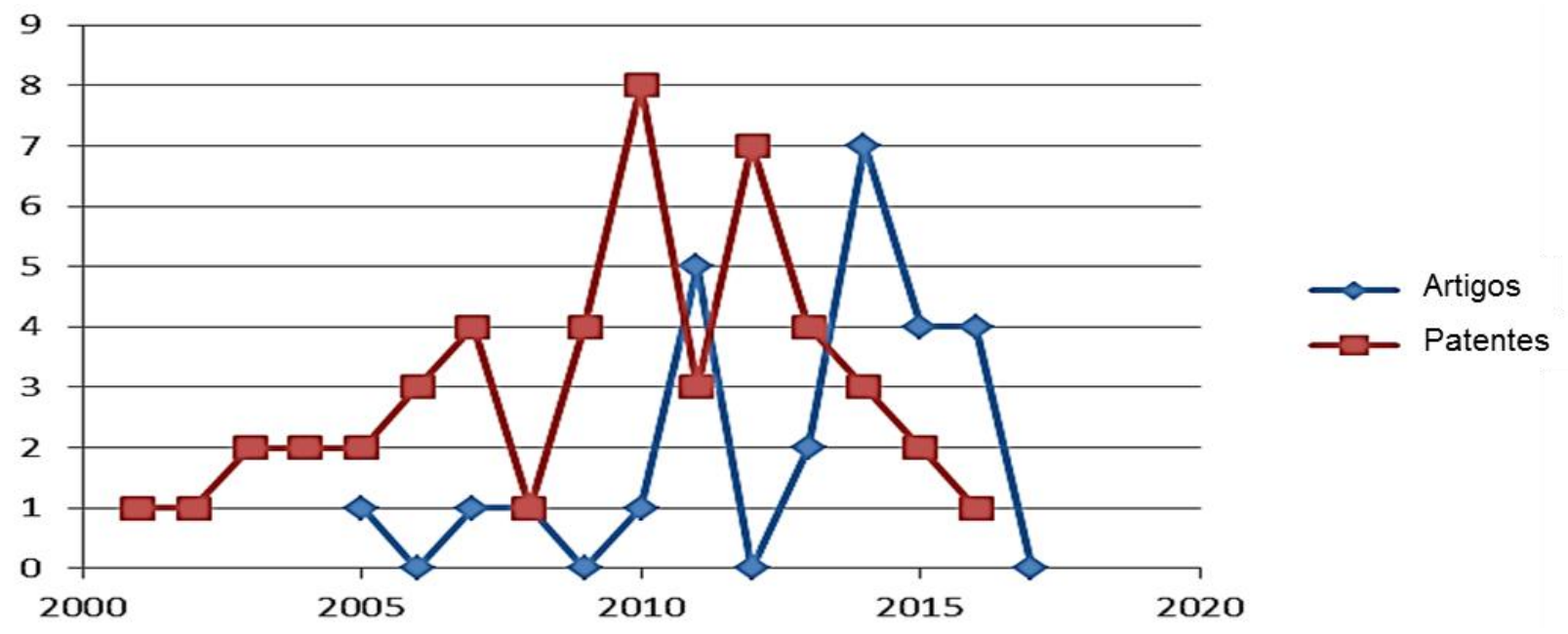

Fonte: Elaborado pelos autores (2017).

O crescimento acentuado na produção de artigos, a partir do ano de 2011, e de depósitos de patentes, a partir de 2010, demonstra o grande interesse de pesquisa e de produção relacionadas à tecnologia. Esse grande interesse na tecnologia de produção de PLA por leveduras em glicerol, atestado por essas informações colhidas nas bases de dados, é característico das tecnologias emergentes. Segundo alguns autores (QUINTELLA, 2009; JESUS, 2009), o crescimento expressivo na produção de patentes e artigos de uma determinada tecnologia é uma característica de tecnologias emergentes em seus primeiros anos de "apropriação".

Analisando os pontos propostos no presente trabalho detalhando: o país/continente, ano da publicação, instituições que mais publicam ou inventores independentes, estabelecendo relações de proporções entre as publicações de artigos indexados e de patentes, com o detalhamento das tecnologias dos artigos e das patentes, das revistas e das editoras que mais publicam na área, é possível fazer-se mapas tecnológicos, com as seguintes aplicações:

O roadmap se aplica a um novo produto ou processo, ou a uma tecnologia emergente. Observa-se o desenvolvimento de um roteiro que apresenta três focos principais: (a) contribuir para chegar a um consenso sobre um conjunto de necessidades e sobre as tecnologias necessárias para satisfazê-las; (b) alicerçar a previsão da evolução tecnológica; e (c) fornecer um quadro para nortear o planejamento e coordenar a evolução da tecnologia (QUINTELLA, et. al., 2011, p. 25).

Para a análise relativa ao estágio de desenvolvimento e ciclo de vida da tecnologia foi utilizada a conceituação Roussel (1984) citado por CGEE (2014, p. 16), “a maturidade tecnológica pode ser

DOROTEU, L.R et al.. Estudo prospectivo de ácido lático produzido por leveduras em glicerol bruto. 
avaliada segundo o estágio de desenvolvimento e aplicação no ciclo de vida da tecnologia. Ele descreve quatro fases sequenciais de maturidade tecnológica, a saber: (i) embrionária; (ii) crescimento; (iii) madura; e (iv) pós-madura."

Outra forma de se aferir uma tecnologia é observar a sua oferta no mercado. Atualmente, já é possível encontrar com certa frequência sacolas de mercado e embalagens de alimentos feitas a partir de PLA produzido em fonte de carbono, comumente em substrato à base de amido e por processo sintético. De toda forma, o processo envolve a produção de ácido lático por meio de bactéria, algas ou leveduras, para depois submetê-lo ao processo de polimerização.

As vantagens de utilização das leveduras, conforme proposto, é que a partir de um resíduo industrial, glicerol bruto, produz o monômero L-ácido lático com alto grau de pureza apresentando melhor biocompatibilidade com o organismo humano. As bactérias produzem misturas racêmicas, o que dificulta o processo posterior de polimerização, e utilizam como substrato amidos e derivados, os quais são fontes concorrentes a alimentação.

Tabela 4 - Matriz SWOT para o PLA produzido por leveduras em glicerol bruto.

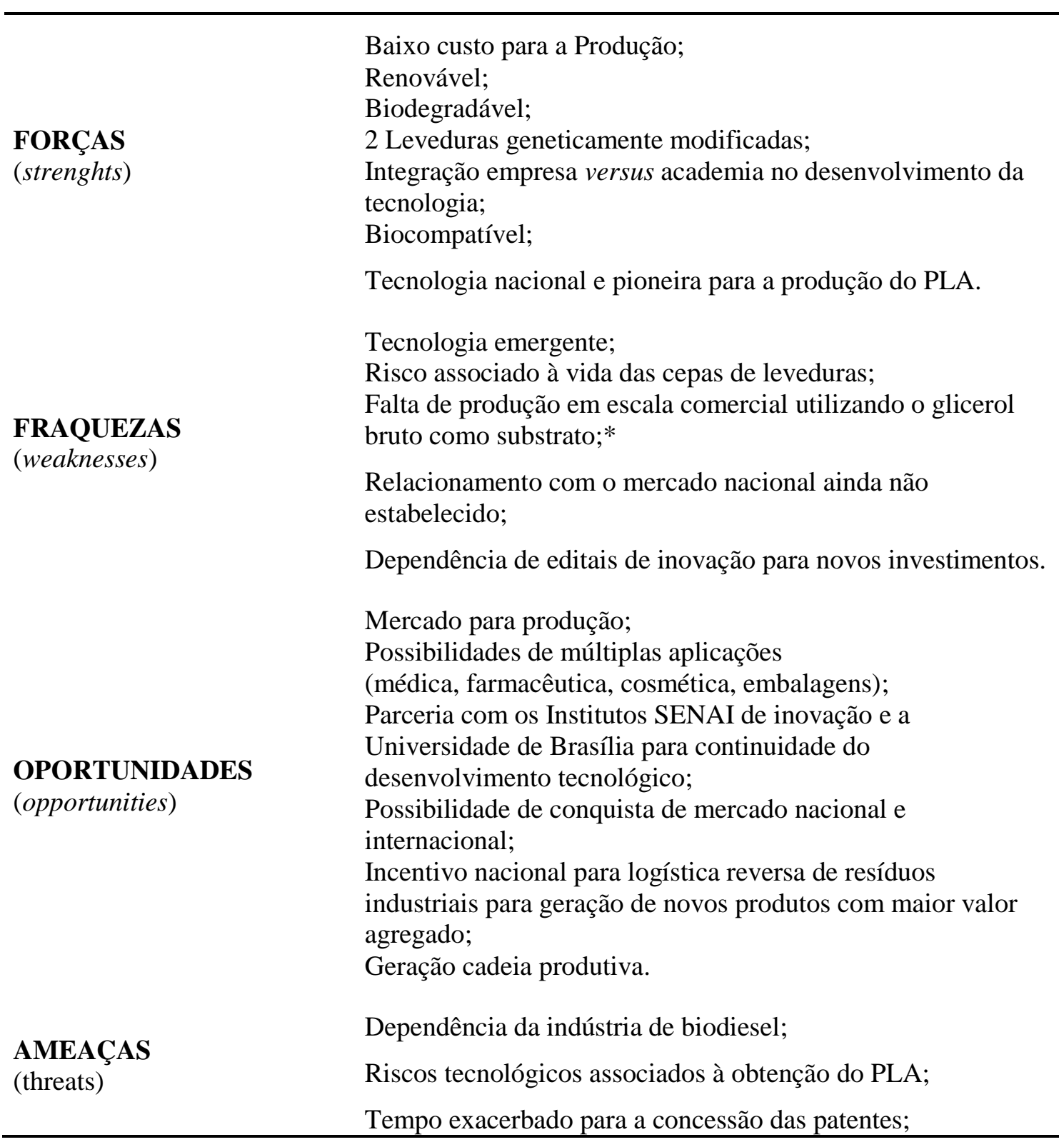

DOROTEU, L.R et al.. Estudo prospectivo de ácido lático produzido por leveduras em glicerol bruto. 
Poder de concorrência: mercado dominado por um único player;

Novos fornecedores e concorrentes;

Tecnologias e soluções avançadas.

Fonte: Elaborado pelos autores (2017).

* Foram realizados testes de escala em 100L, porém utilizando como substrato derivados de amido. Como o desenvolvimento tecnológico ainda está em andamento, os próximos ajustes serão utilizando o substrato proposto oriundo do processo produtivo da cadeia do biodiesel.

A partir da consideração do número de artigos publicados em bases indexadas, do número de depósito de patentes nas bases pesquisadas, das possibilidades de aplicação da tecnologia e do mercado disponível verifica-se a possibilidade de abertura de novos mercados relacionados à aplicação no corpo humano, com base no ciclo de vida da tecnologia. Afere-se o seu nível de desenvolvimento, em relação ao ciclo de vida da tecnologia, como uma tecnologia em estágio embrionário. Trata-se de um estudo claramente ainda em desenvolvimento, que como é natural que seja, devido o interesse econômico, existam algumas poucas organizações no mundo explorando comercialmente a tecnologia de produção de PLA em glicerol por meio biológico, utilizando-se de leveduras.

Em relação à analise da prontidão tecnológica, a ferramenta indicada é o da tecnologia Technology Readiness Levels (TRL), uma escala com variação de 1 a 9 desenvolvida pela Agência Espacial Americana (NASA) colocada em prática em teste de materiais, a qual serve como exemplo de aplicação (GIL, ANDRADE, COSTA, 2014).

Com base nas patentes analisadas, mais detidamente tendo como referência o fato de que essas patentes analisadas competem com outras que guardam proximidade entre si, é possível concluir que o maior recorte das tecnologias de produção de PLA em glicerol a partir de leveduras estão entre os TRL4 a TRL6, que segundo Quintella (2017, p.1) corresponde ao "desenvolvimento tecnológico focado em pesquisa aplicada e onde a transferência de tecnologia tem ainda grande viés acadêmico requerendo rodadas de negociação de Portfólios de PI e mentorias, startups; tradicionalmente denominada de piloto, por exemplo."

Atualmente, o Brasil importa PLA e o valor elevado cobrado pela empresa pioneira no setor e o anseio de pessoas para terem acesso à tecnologia de preenchimento facial faz com que se desenvolvam pesquisas para aplicação médica de PLA. A constatação de que empresas incubadas tem pesquisas sendo desenvolvidas para o aumento da escala de produtividade em ambiente relevante para a exploração industrial, fazem-nos chegar à conclusão que a maior parte do recorte analisado no presente trabalho está entre o TRL 4 a 6.

\section{CONCLUSÃO}

As pesquisas relativas à sua produção por meio de fermentação e métodos e mecanismos de extração e purificação desse ácido lático produzido são mais recentes com depósitos de patentes a partir de 2001, e a primeira publicação de artigo datada de 2005. Observou-se um pico na produção de patentes em 2005/2006, mas o crescimento significativo no depósito de patentes foi no triênio de 2010/2012. O maior número de artigos concentrou-se nos anos 2011 a 2015.

Apesar de a bibliografia e dos números governamentais afirmarem que a política de Pesquisa, Desenvolvimento de Inovação (PD\&I) no Brasil está aquém das políticas dos países orientais "Países como Coréia do Sul e Japão tem demostrado um grande crescimento de depósitos de patentes, devido a sua política de incentivo a inovação e tecnologia, diferentes do Brasil," a China

DOROTEU, L.R et al.. Estudo prospectivo de ácido lático produzido por leveduras em glicerol bruto. 
responde por um terço do depósito de patentes no mundo, grande parte com proteção apenas em seu território (CARDOSO; SOUZA; GUIMARÃES, 2017).

No caso analisado, a produção de PLA por leveduras tendo como fonte de energia o glicerol, com destaque no Brasil, atribuindo-se o fato a sua vocação para o desenvolvimento de biocombustíveis e a tecnologia ser uma oportunidade para resíduos descartados da produção de biodiesel. Em adição, reporte-se que as instituições que se destacaram tratam-se de empresas privadas autofinanciadas e instituições de educação que mesmo com pouco ou nenhum financiamento governamental têm alta vocação nas atividades voltadas à pesquisa.

\section{REFERÊNCIAS}

CARDOSO, L. G.; DE SOUZA, C. O.; GUIMARÃES, A. G. Prospecção tecnológica de patentes sobre a utilização de embalagens antimicrobianas em alimentos. Cadernos de Prospecção, v. 10, n. 1, p. 14, 2017.

CGEE. Centro de Gestão e Estudos Estratégicos. Parcerias Estratégicas. Brasília: de Gestão e Estudos Estratégicos: Ministério da Ciência, Tecnologia e Inovação. v. 19 n. 39 (dez 2014) Semestral. ISSN1413-9375

DATTA, R.; HENRY, M. Lactic acid: recent advances in products, processes and technologies-a review. Journal of Chemical Technology and Biotechnology, v. 81, n. 7, p. 1119-1129, 2006.

DOS REIS, D. R.; DE VINCENZI, T. B.; PUPO, F. P. Técnicas de Prospecção: Um Estudo Comparativo. Revista de Administração Contemporânea; v. 20, n. 2, p. 135-153, 2016.

ESPACENET [Base de dados - Internet]. European Patent Office; 2016. Disponível em: <https://worldwide.espacenet.com/> Acesso em jul. 2017.

FRANCHETTI, S. M. M.; MARCONATO, J. C.. Polímeros biodegradáveis - uma solução parcial para diminuir a quantidade dos resíduos plásticos. Quím. Nova, São Paulo, v. 29, n. 4, p. 811-816, July 2006. Available from <http://www.scielo.br/scielo.php?script=sci_arttext\&pid=S0100$40422006000400031 \& \operatorname{lng}=$ en\&nrm=iso $>$ access on $29 \quad$ June 2017. http://dx.doi.org/10.1590/S0100-40422006000400031.

GIL, L.; ANDRADE, M. H.; COSTA, M. do C. Os TRL (Technology Readiness Levels) como ferramenta na avaliação tecnológica. Revista Ingenium, p. 94-96, 2014.

GOOGLE ACADÊMICO. [Base de dados - Internet] Google Inc.; 2017. Disponível em: <http://scholar.google.com.br/> - Acesso em Jun. 2017.

GUIMARÃES, R. P.; FONTOURA, Y. S. dos R. da. Rio+20 ou Rio-20?: crônica de um fracasso anunciado. Ambient. soc., São Paulo, v. 15, n. 3, p. 19-39, Dec. 2012. Available from $<$ http://www.scielo.br/scielo.php?script=sci_arttext\&pid=S1414-

753X2012000300003\&lng=en\&nrm=iso>. access $\quad$ on $\quad 29 \quad$ Jun. 2017. http://dx.doi.org/10.1590/S1414-753X2012000300003.

JESUS, C. A. C. et al. Prospecção Tecnológica de Biodiesel. Cadernos de Prospecção, v.2, no 1, p. 17-21, 2009.

LIMA, P. B. A. et al. Novel homologous lactate transporter improves l-lactic acid production from glycerol in recombinant strains of Pichia pastoris. Microbial Cell Factories, v. 15, n. 1, p. 158, 2016.

MACHADO, B. A. S. et al. Tendências tecnológicas de embalagens biodegradáveis através da prospecção em documentos de patentes. Cadernos de Prospecção, v. 5, n. 3, p. 132, 2014. 
MACHADO FILHO, Carlos D. et al. Ácido Poli-L-Láctico: um agente bioestimulador. Surg. cosmet. dermatol.(Impr.), v. 5, n. 4, p. 345-350, 2013.

PARACHIN, N. S. Levedura no Glicerol. Pesquisa FAPESP, São Paulo, p. 12 - 12, 30 abr. 2014. Disponível em: http://revistapesquisa.fapesp.br/2014/04/24/levedura-glicerol/

PATENTSCOPE [Base de dados - Internet]. WIPO; 2017. Disponível em: <https://patentscope.wipo.int/> Acesso em jul. 2017.

QUINTELLA, C. M. et al. Cadeia do biodiesel da bancada à indústria: uma visão geral com prospecção de tarefas e oportunidades para P\&D\&I. Química Nova, v. 32, no 3, p. 793-808, 2009.

QUINTELlA, C. M.; CERQUEIRA, G. S.; MIYAZAKI, S. F.; HATIMONDI, S. A.; MUSSE, A. P. S.; Captura de CO2: Panorama (Overview) - Mapeamento Tecnológico da Captura de CO2 baseado em patentes e artigos, 1a. ed., Editora da UFBA: Salvador, 2011.

ROCHA, A. M.; QUINTELLA, C. M.; TORRES, E. A. Prospecção de artigos e patentes sobre polímeros biocompatíveis aplicados à Engenharia de Tecidos e Medicina Regenerativa. Cadernos de Prospecção, v. 5, n. 2, p. 72, 2014.

SURYANEGARA, L.; NAKAGAITO, A. N.; YANO, H. The effect of crystallization of PLA on the thermal and mechanical properties of microfibrillated cellulose-reinforced PLA composites, Composites Science and Technology. v. 69, p 1187-1192, 2009.

WEB OF SCIENCE [Base de dados - Internet]. Clarivate Analytics; 2017. Disponível em: $<$ https://webofknowledge.com> Acesso em jun. 2017. 